\title{
PLANTAE CENTROBRASILIENSES MINUS COGNITAE SEU NOVAE
}

\author{
CARLOS TOLEDO RIZZINI \\ Pesquisador do Jardim \\ Botânico do Rio de Janeiro
}

Durante os labores empreendidos na área do cerrado, no planalto central brasileiro, algumas espécies particularmente notáveis se apresentaram ao exame dos botânicos envolvidos. Convém divulgar os estudos levados a cabo com tais entidades pouco encontradiças, cujo conhecimento ainda é nulo ou insatisfatório.

\section{Astrocaryum kewense B. Rodr.}

Sertum Palm. Brasil., 2: 70, 1903.

No curso de vários anos, o eminente pesquisador da flora do cerrado e dasônomo Ezechias P. Heringer, partícipe de muitos trabalhos em comum sobre aquela formação vegetal, fazia referências a certa palmeira anã que conhecia nas imediações de João Pinheiro, MG. Declarava, em síntese, ser uma espécie de área mui restrita, apenas localizada naquele trecho, tendo de peculiar a extrema semelhança com o diminuto gênero Acanthococus B. Rodr., freqūente no cerrado paulista (raro em Minas Gerais), embora alcance alguns campos do Paraguai.

Em princípios de setembro de 1979, viajávamos juntos entre Brasília e Paraopeba e, assim, surgiu a oportunidade de examinarmos em conjunção dita planta. Deveras, era completa a semelhança exterior com Acanthococus. Seguem-se os resultados do estudo levado a cabo na pequenina população descoberta por Heringer.

No município de João Pinheiro, entre os $\mathrm{Km} 170$ e 152 da rodovia Brasília-Belo Horizonte, podem ser encontradas mais de 1 palmeiras anãs ("acaules"), isto é, providas de pequeno caule subterrâneo, cuja principal feição - além do habitat intraterrestre - é a posse de volumosa gema terminal; só as folhas recurvadas e (na presente) fortemente aculeadas estão no ar. Semelhante tipo caulinar (Figs. 1 e 2) está bem representado nas figuras de Rawitscher \& Rachid (1946) e de Toledo (1952), no concernente a Acanthococus emensis Tol.

Descrição de Astrocaryum kewense - As folhas (Figs. 2 e 3) medeiam entre 1 e $1,50 \mathrm{~m}$, ficando em geral acima de $1 \mathrm{~m}$. Constam de 70-80 segmentos opostos e ordenados em duas séries longitudinais ao longo das margens do peciolo, os quais se mostram decorrentes no pecíolo até cerca de $2 \mathrm{~cm}$. São lineares, subulados no ápice, 
coriáceos, com a nervura central na página superior proeminente e pulverulento-tomentela; na página inferior o indumento dispöe-se em estrias longitudinais. Os segmentos (ou pinas) basais medem $6.15 \mathrm{~mm} \times 20-33 \mathrm{~cm}$; os medianos vão a 12-15 $\mathrm{mm} \times 38-50 \mathrm{~cm}$; e os terminais apenas a $6 \mathrm{~mm} \times 30-36 \mathrm{~cm}$; os maiores in vivo atingem $55 \mathrm{~cm}$. O pecíolo, na porção basal, é fundamente canaliculado e completamente revestido de um indumento pulverulento-tomentoso de cor cinzentoclara levemente rosada; af leva numerosos acúleos negros, não raro tortuosos, duros, pungentes e plano-convexos na seção, os quais ficam entre 1 e $10 \mathrm{~cm}$ de comprimento, a maioria entre $3,5-7(9) \mathrm{cm}$. Na direção do ápice foliar, o pecíolo vai se tornando integro e exibe seção triangular, do mesmo passo que o citado revestimento piloso se mostra esparso. Os acúleos, primeiro até cerca de $3 \mathrm{~mm}$ de espessura e $9 \mathrm{~cm}$ de comprimento, encurtam e adelgaçam-se, terminando com $1.5 \mathrm{~cm}$ somente. A nervura principal acaba lisa, destituída de pêlos.

As espatas (Figs. 2 e 4), inicialmente, são alongadas e fusiformes, depois de abertas têm a forma de barco, medindo, em flor, $20-25 \mathrm{~cm}$ por $3-4 \mathrm{~cm}$ e, quando frutificadas, $6-8 \times 16-20 \mathrm{~cm}$. Revelam-se lenhosas e recobertas de um indumento pulverulento-tomentoso breve e rufo, em geral claro; ornam-se, ao demais, de estrias fusiformes escavadas nos pontos de onde emergiram os acúleos. 0 grosso pedúnculo mede 5-10 cm, levando dito indumento; é aculeado na base. As espatas possuem grande cópia de acúleos, sobretudo nas proximidades do ápice e quando ainda fechadas; muitos desles são tortuosos, o que parece ser um caráter especifico (não visto em nenhum outro membro de Astrocaryum, sendo que alguns emitem espatas inermes), e alcançam de $5 \mathrm{~mm}$ a $8,5 \mathrm{~cm}$ de comprimento (pelo comum, até $3,5-4 \mathrm{~cm}$ ). Têm inserção débil e caem com certa facilidade. As espatas em fruto dobram-se notavelmente, ficando mais curtas e mais largas.

A inflorescência dentro da espata assenta sobre pedúnculo de uns $5.7 \mathrm{~cm}$, que pode ser dotado de acúleos aplicados. Os ramos numerosos ou espigas andam por 4-5 $\mathrm{cm}$ e possuem longa vilosidade bastante manifesta. As flores estão inseridas no interior de fóveas ou alvéolos membranáceos, bastante fundos. Em geral, há grande número de flores masculinas acompanhadas de algumas flores femininas, as quais estão situadas junto à base das espigas.Todavia, ocorrem espádices quase inteiramente machos ou fêmas. As espigas estão dotadas de brácteas agudas, espinulosas, de 5-15 $\mathrm{mm}$ de comprimento. As flores estaminadas levam cálice formado de 3 sépalas triangular-acuminadas muito pequenas $(0,5-0,8 \mathrm{~mm})$, aplicadas à base da corola, cujas margens são apenas irregulares e de modo leve. As pétalas convexas são deltóideosuborbiculares e agudas, medindo 1,5-2 mm de comprimento. Os filetes são do tamanho das anteras, mas a porção livre é muito curta; anteras sagitadas na base, em seco ornadas de diminutas pontuaçőes rubras, com o comprimento de $1,3 \mathrm{~mm}$. 0 pistilódio reveste a forma de 3 estiletes abortivos no centro da flor. Ainda com a espata fechada, as flores apicais estavam com as corolas abertas e soltando pólen. As flores pistiladas apresentam cálice e corola subiguais, crassos; o primeiro é cupuliforme, tridentado, as sépalas coalescentes; a segunda conduz pétalas conchiformes e livres. Pétalas e sépalas apresentam a margem superior setulosa ("espinescente"). 
Os frutos, a $4-6$ de setembro, estavam ainda verdes, mas com suas dimensões definitivas ou próximas disso, a julgar mediante endocarpos de safras anteriores achados no solo sob as frondes. São globosos ou algo alongados, um tanto rostrados, ornados na base com o cálice e a corola, ampliados e rasgados, com $6.7 \mathrm{~mm}$ de alto; medem as nozes, em estado fresco, $2,5-3 \mathrm{~cm}$ de comprimento e $2-2,5 \mathrm{~cm}$ de diâmetro (secos, ficam em torno de $12-15 \times 25 \mathrm{~mm}$ ). Há 3 camadas nelas: epicarpo verde e liso (ca.1 mm), mesocarpo branco (ca. $2 \mathrm{~mm}$ ) e endocarpo alvo (1-1,5 mm); por dentro, nessa fase pré-maturação, tão somente endosperma líquido copioso era óbvio. Cada cacho engloba 10 a 25 cocos. Dessecados, exibem o epicarpo granuloso sob lente e de cor fusco-rubente.

Dos endocarpos antigos, apanhados sobre o solo debaixo das palmeirinhas, uns poucos apenas estavam intactos; a grande maioria mostrava orifícios mais ou menos amplos produzidos pelos dentes de roedores do tipo rato selvagem; alguns exibiam pequeninos pertuitos gerados por brocas. Tais órgãos são idênticos a miniaturas do coco-da-baia, ovóides, atenuados numa das extremidades, na outra arredondados, providos de 3 "olhos" (poros germinativos). Mui típico é o revestimento de fibras aderentes e entrelaçadas que partem dos poros de maneira radiada, dando origem a figuras estreliformes. Medem $15 \times 17 \mathrm{~mm}$ até $18 \times 27 \mathrm{~mm}$, alguns sendo aproximadamente globulosos e com $18-20 \mathrm{~mm}$ de diâmetro. Um único trazia o conteúdo preservado e ainda fresco, uma esférula com perto de $13 \mathrm{~mm}$ de diâmetro - novamente parecido ao conteúdo de Cocos nucifera L., incluindo o albúmen oleaginoso e cavitário.

Astrocaryum kewense foi encontrado em cerrado aberto e mais ainda na parte capinada junto à margem da estrada que, de Brasflia, passa em João Pinheiro, MG. No referido km 158, colheram-no E. P. Heringer 17554 \& C. T. Rizzini (6-IX-1979).

A descrição supra-exarada difere da muito mais sumária de Barbosa Rodrigues em alguns detalhes. Reputo tais divergências devidas ao fato de o eminente palmólogo patrício ter prospeccionado, bem contra o seu costume, escasso material herborizado (não preparado por ele). Explica-se, segundo suas anotações (op. cit.): o espécime coletado por Glaziou foi enviado diretamente a Kew Gardens, Londres. Ali o especialista o encontrou e estudou, declarando-o "mal représentée". Desta sorte, o material dessecado não podia ser tão completo quanto o meu, já que examinei dezenas de plantas vivas in situ; só espatas, tive em mãos uma boa dúzia, desde floríferas até frutíferas maduras. Como exemplos, cito o comprimento dos acúleos peciolares e espatais, que Barbosa Rodrigues indica como até 6 e $4,5 \mathrm{~cm}$, respectivamente; e as drupas que dá como tendo $12 \times 20 \mathrm{~mm}$.

O exemplar de Glaziou era proveniente de Goiás. Burret (1934) menciona outro, vindo de uma chapada a 400-600 m de altitude, em Vitória, Inhumas, Maranhão. Só a primeira exsicata deve existir hoje. Daf a importância da presente comunicação, redescrevendo uma entidade especifica quase perdida para a Ciência e repondo material adequado e copioso em coleção idônea, assegurando sua existência e permanência para o futuro. 
A espécie afim, A. campestre Mart., dispersa por Goiás e Minas, foge da presentemente tratada pelos: acúleos peciolares menos numerosos e não maiores que $1.3 \mathrm{~cm}$, segmentos em número de 20 ou pouco mais ou menos, pedúnculo ancipital e cheio de brácteas e flores femininas medindo perto de $1 \mathrm{~cm}$ de comprimento.

OBS. - É um mistério para mim a razão pela qual o ilustrado J. Barbosa Rodrigues repete 4 vezes a expressão Astrocaryum kewensis (terminando em IS) quando usa A. manaoense (desinência SE). Ora, kewensis é adjetivo da mesma classe que manaoensis, e. Sendo Astrocaryum do gênero neutro, assim como compôs A. manaoense deveria formar A kewense que aqui emprego. É evidente que ele o fez intencionalmente - mas, por que?

\section{Cyclolobium nutans Rizz. \& Her., n. sp.}

C. brasiliensi Benth. manifeste proximum, foliis acuminatis duplo triplove magnioribus petiolisque bis longioribus abhorret; habito quoque distinctum. C. clausenii Benth. leguminibus obovoideis duplo majoribus cum petiolis ad $25 \mathrm{~mm}$ longis gaudet.

Arbuscula nec plus $10 \mathrm{~m}$ alta, ramis elongatis pendulisque ad terram vergentibus. Rami teretes, striati, pubescentes. Ramuli canaliculati, dense aureo-fulvo-tomentosi. Internodia 1,5-3,5 cm longa. Folia alterna disticha, oblonga, basi modice attenuata in novellis rotundata, apice acuminata, acumine usque ad $1 \mathrm{~cm}$ longo, margine minute undulata, nervis secundariis atque reticulo venoso utrinque (magis infra) graciliter prominulis, nervo centrali subtus elevato, supra glabra, subtus praecipue ad nervos pubescentia, juventute (florendi tempore) membranaceo- translucida et supra pilosula ad nervos, provectiore aetate subcoriacea ac opaca, $7-13 \mathrm{~cm}$ longa, 3,5-7 cm lata. Petioli canaliculati, pubescentes, 10-15 mm longi. Racemuli axillares, $2-4 \mathrm{~cm}$ longi, fulvo-aureo-pubescentes, 1-3-ni, floribus oppositis. Pedicelli circiter $3 \mathrm{~mm}$ longi, sub apice bibracteolati. Calyx subspathaceus, fulvo-pubescens, $3 \mathrm{~mm}$ altus, lobis triangularibus, sepalo 1 subcucculato instructus. Petala carenalia libera alis similia; alis unguibus longis suffultis, basi appendiculatis, $3 \times 7 \mathrm{~mm}$. Vexillum suborbiculatum, roseum in vivo, unguiculatum, glabrum, striatum $5 \times 5 \mathrm{~mm}$. Stamen vexillare liberum. Tubum staminale ad latus omnino fissum. Antherae breviter apiculatae. Ovarium compressum planum, pilis nonnullis ad margines ornatum, stipitatum. Legumen 7-10 $\mathrm{mm}$ longe stipitatum, irregulariter suborbiculare, coriaceum, glabrum, uno latere anguste alatum, sub ala nervo elevado percursum, $2 \times 2,5-3(3,5) \mathrm{cm}$, monospermum, utrinque ad lentem grosse reticulatum. Semen discoideum, planum, 8-10 mm diametro, testa laevi praeditum.

Habitat ad ripam fluminis Corumbá, 50 km a Luziânia, Goiás, prope civitatem Brasília, D. F., ab E. P. Heringer 15944 (9-1X-1976) lectum; holotypus in RB, 193688.

O novo táxon, no interior de um gênero pequeno, homogêneo e constituído de espécies imprecisamente definidas, separa-se pelo hábito peculiar (Fig. 5) e pelas folhas mais robustas (Fig. 6) da única possível em virtude das dimensōes reduzidas 
dos frutos, ou seja, Cyclolobium brasiliense Benth. As demais, como C. clausenii Benth. e C. blanchetianum Tul., são portadoras de legumes pelo menos duas vezes maiores, afora outros fatos morfológicos de menor peso, como calvície e comprimento de pecíolos. É a única conhecida das matas ciliares da região do Distrito Federal e de Goiás.

\section{Pouteria undulatifolia Rizz., n. sp.}

Prope P. melinonianam (Pierre) Baehni e Guiana Gallica evidenter inserenda in systemate baehniano; autem discernitur foliis petiolisque brevioribus, lamina foliorum usque ad maturitatem fortiter undulato-bullata (vetustior fere plana), apice longissime porrecto caudata et vulgo falcata, filamentis staminum longioribus tubo corollae affixis. P. venulosae (Mart. \& Eichl.) Baehni sat similis sed sepalis petalisque 5, prioribus intus villosis, staminodiis triangularibus acutisque, pedicellis brevioribus, filamentis elongatis, discrepat.

Arbor cc. $15 \mathrm{~m}$ alta, in substrato saxoso $5-8 \mathrm{~m}$ tantum attingens, $15 \mathrm{~cm}$ diametro, ramis fuscescentibus teretibus apicem versus pubescentibus mox glabratis canaliculatis, novellis (prima juventute) minute sericeo-rufo-puberulis. Folia anguste oblonga vel lanceolata, utrinque attenuata, basi cuneiformia, versus apicem longissime caudata, acumine $1.2 \mathrm{~cm}$ longo saepeque falcato ad extremitatem obtusiusculo, subcoriacea, secundum costam elevato-depressa sed maturitate paene plana, supra nervo centrali plano et secundariis impressis valde numerosis, subtus centrali lateralibusque leviter prominulis numerosissimis, costa imprimis basin versum pilis rufis sparsis induta, margine incrassata nervo gracili a secundariis superstructo percurso, colore plus minusve fusco-rubente infra pallidiore vel nitidiore, $6-10 \mathrm{~cm}$ longa, $2-3,5 \mathrm{~cm}$ lata. Petioli supra canaliculati, 3-6 mm longi. Flores ad axillas in fasciculos 9-15-floros ordinati. Pedicelli 1,5-2(3) mm longi. Sepala 5, carnosula, conchaeformia, rotundata, círca $1,5 \mathrm{~mm}$ longa, utrinque sericeo-villosa intusque magis sericantia. Petala 2 (3) $\mathrm{mm}$ longa, tubo $1 \mathrm{~mm}$ longo, lobis rotundatis, glabra. Staminodia deltoidea, apice manifeste acuta Filamenta bene evoluta, antheris aequilonga vel longiora, tubo affixa. Antherae ovatae, acutae tantum, breviter apiculata. Ovarium dense rufo-villosum, 5-loculare. Stylus propter $1,5 \mathrm{~mm}$ longus, stigmate punctiformi coronatus. Baga globosa, in vivo lutea, plus aut minus $1 \mathrm{~cm}$ diametro.

Crescit in Serra de Caldas Novas, Termas do Rio Quente, Goiás, ad cerradão (cerrado sive savanna arboribus elatis crassisque, approximatis ut in silva), legit E. P. Heringer 16657 (5-1-1977); holotypus in RB 193690.

Parátipos - Catetinho, Brasília, D.F., silva ciliaris, collegit E. P. Heringer 14866 (25-X-1975); IBGE. Serra de Caldas Novas, Goiás, in silva atque in cerrado denso, ab E. P. Heringer 12231 (2-XI-1972) lecta (jam fere tota deflorata); IBGE.

Ao primeiro exame, a presente árvore (Fig. 7) seria denominada Pouteria venulosa, entidade de ampla dispersão no território nacional, pela grande semelhança que ambas demonstram. As únicas divergências realmente dignas de consideração são: a existência de 4 sépalas interiormente glabras em P. venulosa e 5 interiormente rufo-vilosas em P. undulatifolia Diferenças, não há duvidar, de pequena montar 
mas de alta relevância taxionômica, num grupo tão homogêneo $\mathrm{e}$ rico, porque caracterizam uma seção (Gomphilucuma). Além disso, pequenos fatos morfológicos como comprimento de pedicelos e de filetes, e a forma de estaminódios - vêm corroborar a discriminação proposta. De P. melinoniana, em cuja seção se situa, a espécie nova se afasta mais decididamente, conforme a introdução da diagnose latina explica. Esta leva folha e peciolos e filetes maiores, além dos limbos foliares patentemente ondulados e bulados.

Cordia glabrata (Mart.) Dc.

Prodromus, 9: 473, 1895.

Árvore de uns 6-10 m de altura; ramos estriados com poucas lenticelas e grandes cicatrizes deixadas pelas folhas caídas, cuja margem é elevada; râmulos negros, profundamente multicanaliculados, pouco pilosos e com corpos fulvo-seríceo-tomentosos que incluem, ao que parece, as gemas axilares. Entrenós dos ramos $2-4 \mathrm{~cm}$ e dos râmulos em torno de $8 \mathrm{~cm}$ de comprimento. Folhas largamente ovado-oblongas ou mui largamente oblongas, na base arredondadas, subcordadas e freqüentemente inequiláteras, na direção do ápice um pouco estreitadas e obtusas, membranáceas na floração e depois moderadamente coriáceas, as nervuras secundárias 6-8 muito frouxas com a central em ambas as páginas algo saliente, em cima pouco pilosas ao longo da nervura principal, porém, toda cheia de pontuaçōes pequeninas e pálidas, em baixo só algo mais pilosa acompanhando as nervuras e sem pontuações, as quais medem 10-15 $x \quad 12.20 \mathrm{~cm}$. Pecíolos multicostados, em cima canaliculados, quase glabros, medindo 5-7 cm. Cimeiras dispostas em racemos axilares fasciculados, que medem 5-10 (15 cm e são densamente fulvo-vilosos, com nós distantes entre si $8-25 \mathrm{~mm}$. Cálice com 11-12 (14) $\mathrm{mm}$, os lobos exíguos $3-5$ denticulados, multissulcado e muito rufo-seríceo-tomentoso. Corola in natura alva, cerca de $3 \mathrm{~cm}$ no comprimento, o limbo perto de 3,5 cm no diâmetro, os lobos mais ou menos $2 \mathrm{~cm}$ de comprimento e $9-10 \mathrm{~mm}$ de largura, sob lente venulosos. Filetes inseridos junto à fauce, glabros, com $4.5 \mathrm{~mm}$. Anteras de $3 \mathrm{~mm}$ Estilete e ovário sem pêlos. Fruto fusiforme, liso, cerca de $7 \mathrm{~mm}$ de comprimento, provido no ápice da base estilar persistente.

Encontrada não longe das margens do Rio Paracatu, próxima à cidade do mesmo nome, Minas Gerais, no cerrado alto e denso e margens da estrada; colheram-na E. P. Heringer 17461 \& C. T. Rizzini (31-VIII-79). Achada ainda nos cerrados de Goiás, mas não é freqüente neles. Ademais: PI, CE, MS. Nome vernacular: louro.

Cordia glabrata pertence a um grupo de espécies bem caracterizado pelo tipo de corola marcescente. Quase todas elas se revestem de típicos tricomas estrelados. A presente entidade nem é glabra nem leva pêlos desta categoria. Possui pequena quota de pêlos alvos e simples ao longo das nervuras, sobretudo na página inferior - mas o importante é que exibe pontuações numerosas na face superior, bem perceptíveis à mera lupa manual. As grandes e finas folhas, entre oblongas e suborbiculares, na base subcordadas e não raro assimétricas, năo deixam de ser diagnósticas. Os exemplares goianos têm o cálice principalmente trilobado. É curioso consignar que em inúmeras 
viagens ao longo da rodovia Belo Horizonte-Brasília nenhum de nós tenha, jamais, visto esta arvoreta, em 1979 presente até na margem da estrada; sua copiosa floração alva não deixaria de atrair nossa atenção para ela. Parece, em suma, ter-se disseminado nos últimos anos, época em que nossas excursões se deslocaram do trato em tela para alhures.

Peschiera campestris (Rizz.) Rizz., stat. nov.

P. affinis (M. Arg) Miers var. campestris Rizz Simpósio sobre o Cerrada, Edit. Univ. de São Paulo, p. 175, 1963.

Subarbusto campestre muito comum no território do Distrito Federal, onde tem sido prescrito e propagado como planta ornamental em face das belas e perfumadas inflorescências. O sistema subterrâneo difuso está descrito e figurado em Rizzini \& Heringer (1966). Ferreira \& Machado (1976) estudam-no como ornamento hortense, - que é facilitado pelo sistema natural de reprodução vegetativa mediante raízes gemiferas; as estacas radiculares estabelecem-se em boa proporção em os novos habitats, inclusive no Rio de Janeiro. As sementes germinam sem dificuldade. Tiradas as mudas com torrão de terra, instalam-se facilmente. É o jasmin-do-cerrado.

Difere de Peschiera affinis por caracteres que, agora reavaliados, cominam a separação em espécies distintas. P. campestris é um mero subarbusto que atinge até cerca de $1 \mathrm{~m}$ de altura, dotado de sistema radicular amplo, extenso, superficial e bastante espesso, fundamentalmente gemífero, formando, no ar, clones de grande amplitude. A outra é arbusto ou arvoreta de 3-6 m tão somente. Leva folhas sésseis e com base arredondada, medindo em geral $6.10 \mathrm{~cm}$ de comprimento por $3.5 \mathrm{~cm}$ de largura (chegando a $6,5 \times 14 \mathrm{~cm}$ ); as folhas de P. affinis são mais estreitas e cuneiformes na base, além de pecioladas $(6-15 \mathrm{~mm})$. As inflorescências da nova espécie se revelam muito mais amplas e maciças e as flores algo maiores. No antigo táxon, as folhas são finas, mais membranáceas do que coriáceas; no agora proposto, elas se mostram bem mais espessas. Peschiera campestris é mais uma espécie campestre e anã que pertence a um gênero cujo hábito característico é arbóreo ou pelo menos arbustivo - do tipo de Chrysophyllum soboliferum Rizz., Parinari obtusifolia Hook., Annona pygmaea Warm., Simaba suffruticosa Engl., Andira humilis Benth., Stryphnodendron platyspicum Rizz \& Her., S. confertum Her. \& Rizz., Anacardium humile St.-Hil., Kielmeyera neriifolia Camb. et passim. A Fig. 8 mostra a planta em exame no mês de novembro, ainda em plena floração.

\section{SUMMARY}

A very small population of the dwarf palm Astrocaryum kewense B. Rodr. was found beside the road that passes near the town João Pinheiro, in Minas Gerais. The plant was collected only twice formerly, but at least Burret's specimen is lost. As it is extremely rare and threatened of extinction, a new description was made with full details, and a complete dried specimen was secured. As species new to science were described Cyclolobium nutans, with small pods and acuminate, hairy leaves, along 
with Pouteria undulatifolia which possesses leaves wavy at margins, bullate in upper surface, and caudate-falcate at apex. Cordia glabrata was redescribed based on a specimen from cerrado. Peschiera affinis var. campestris, restudied, proved to deserve specific status under the name of P. campestris; this is a mere undershrub endowed with a greatly expanded subterranean system composed of thick, richly branched, gemmiferous roots through which the plant reproduces itself vegetatively with copious wealth.

\section{BIBLIOGRAFIA}

BAEHNI, C. 1942 - Mémoire sur les Sapotacées: le genre Pouteria. Candollea, 9: 147-476.

BRADE, A.C. 1932 - Os gêneros Cordia e Tournefortia no Herbário do Museu Nacional, 8: $13-47$.

BURRET, M. 1934 - Die Palmengattung Astrocaryum G.F.W. Meyer. Repert. Sp. Nov. Regni Veget., 35: 114-158.

FERREIRA, M.B. \& W.B. 1976 - Peschiera affinis var. campestris Rizz., uma Apocynaceae ornamental. Anais XXV Congr. Nac. Bot., Mossorb, RN, p 375.380. Ct. Cerrado, 6 (25): 79, 1974, também.

GLASSMAN, S.F. 1972 - A revision of B.E. Dahlgren's Index of American Palms. Phanerog. Monogr., Ed. J. Cramer, 6: 1-294.

HOEHNE, F.C. 1941 - Leguminosas Papilionadas. Flora Brasilica $25(3): 3439$.

RAWITSCHER, F. \& M. RACHID, 1946 - Troncos subterrâneos de plantas brasileiras. Anais Acad. Bras Clências $18(4): 261-280$

RIZZINI, C.T. 1963 - A flora do cerrado. Simposio sobre o Cerrado, Edit. Univ. Ssio Paulo, p. $125-177$.

RIZZINI, C.T. \& E.P. HERINGER, 1966 - Estudo sobre os sistemas subterråneos difusos de plantas campestres Anais Acad. Bras Cièncias 38 (supl.): 85.112

TOLEDO, J.F. 1952 - Estudos sobre algumas palmeiras do Brasil. II. Notas sobre o gênero Acanthococus Bart Rodr. Arquivo Bot Estado Sร̄o Paulo, ns, 3 (1): 3-9. 


$$
k
$$




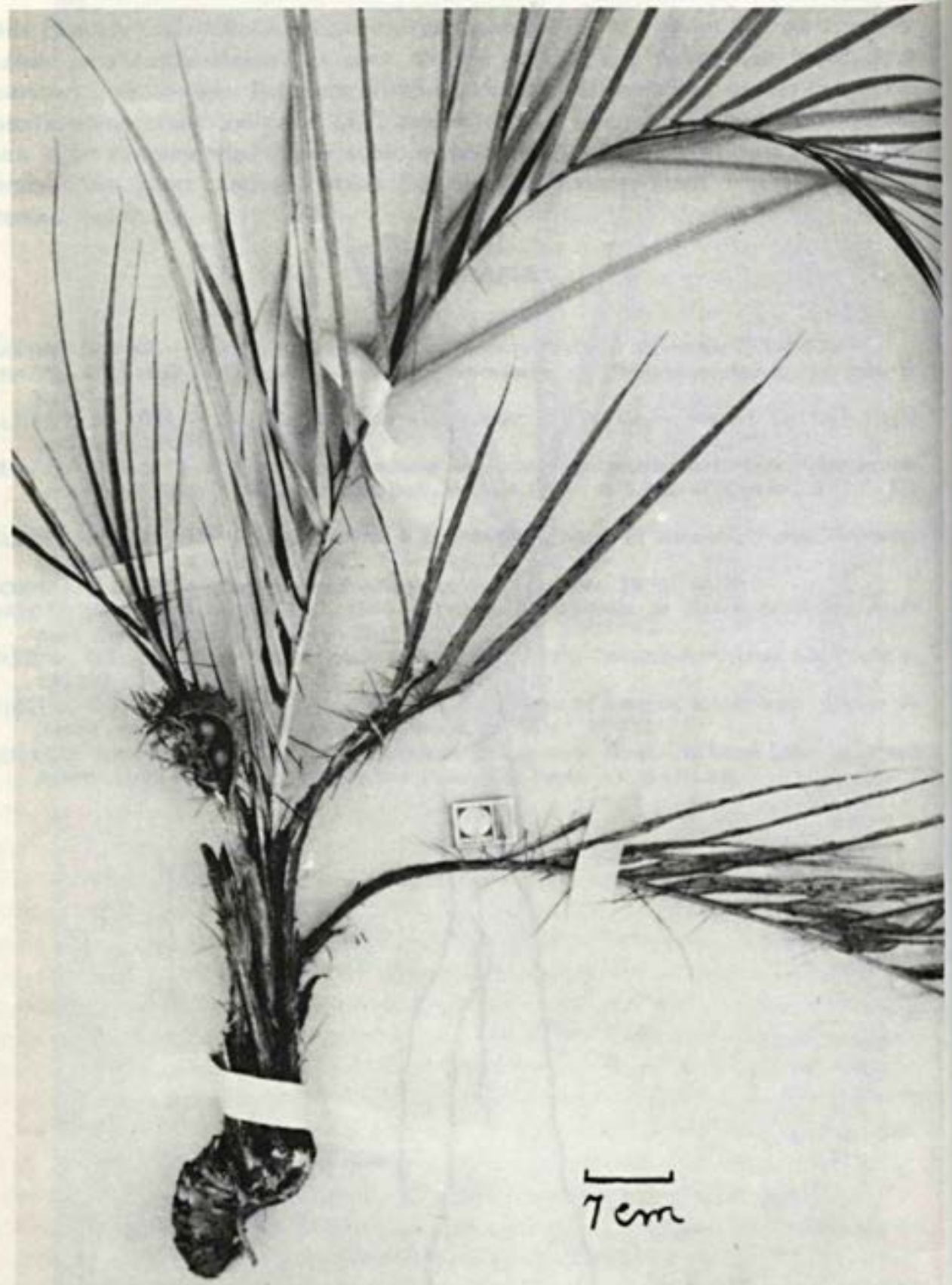

Fig. 2 - Astrocaryum kewense B. Rodr. Planta adulta isolada. Pequeno caule e grande gema terminal. Uma espata frutífera. 


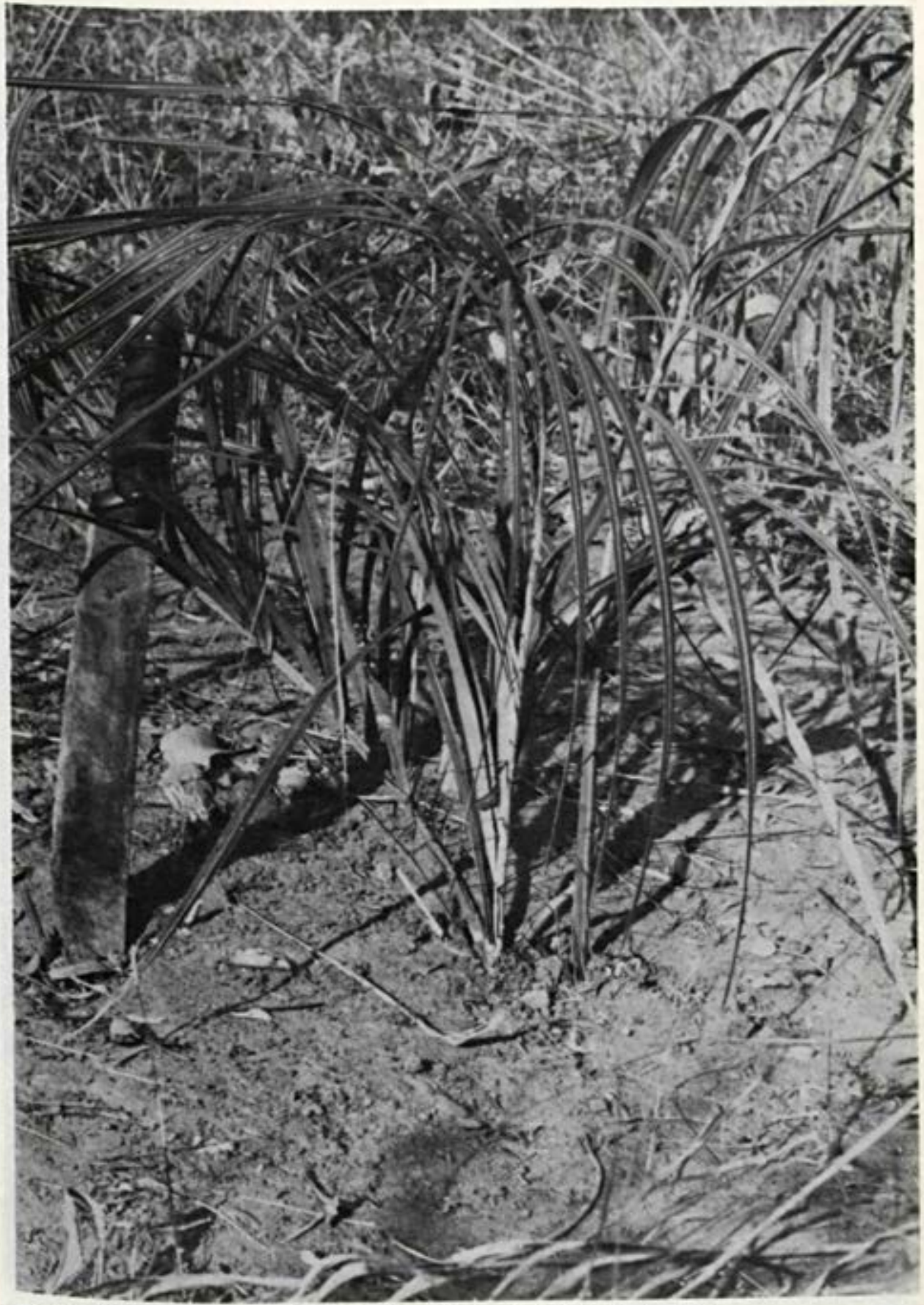

Fig. 3 - Astrocaryum kewense B. Rodr. Palmeira in situ. Joð̄o Pinheiro, MG. 


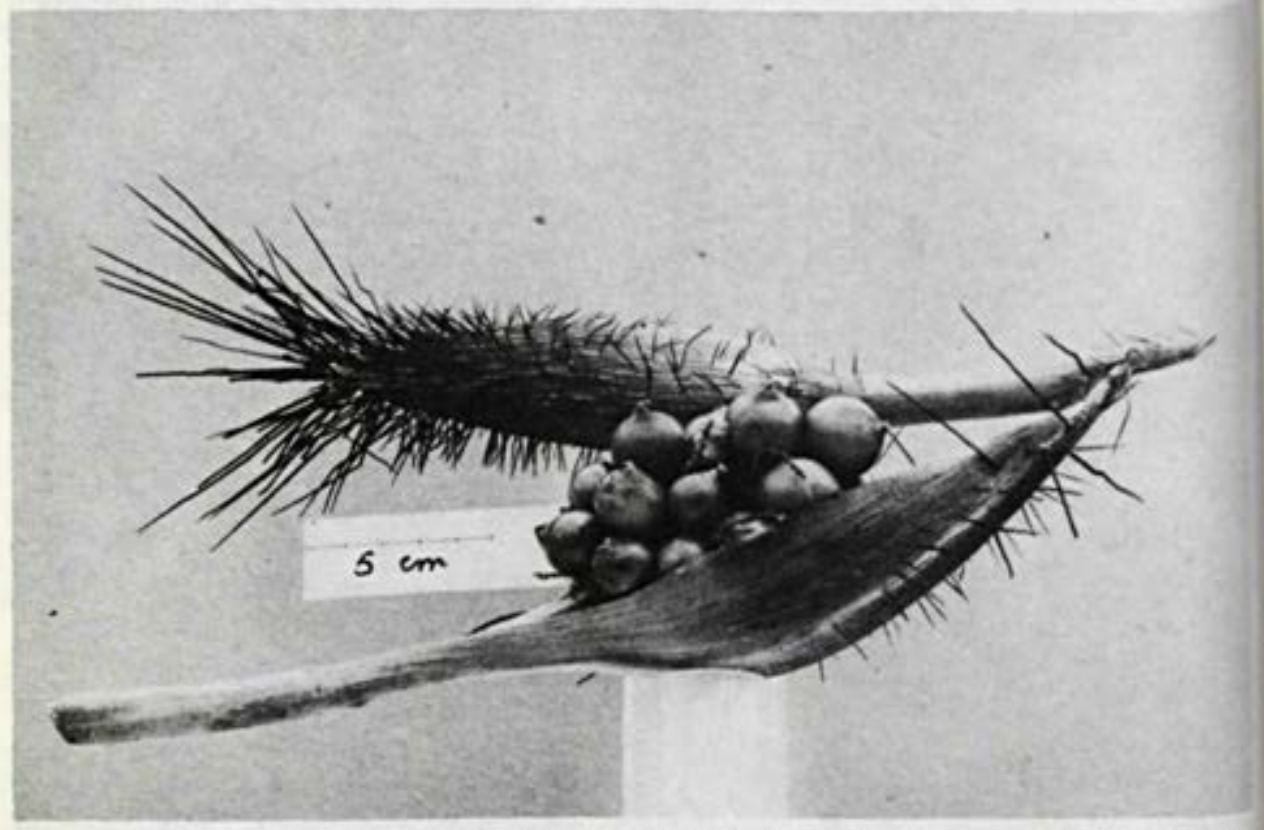

Fig 4 - Astrocaryum kewense B. Rodr. Uma espata florifera (em cima) e outra frutifera (em bai $\times 0$ ). 


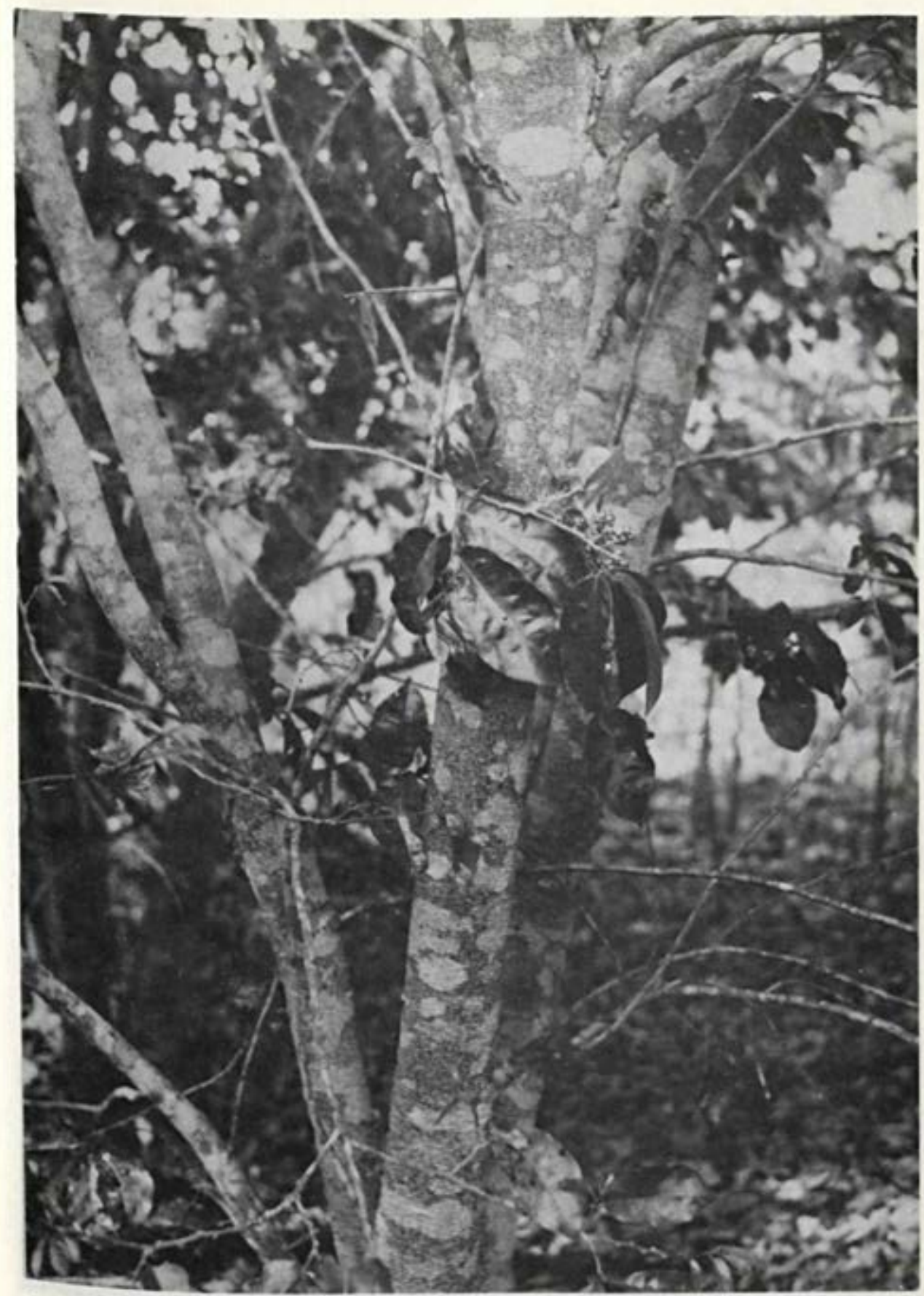

Fig. 5 - Cyclolobium nutans Rizz. \& Her. Hábito, casca e folhas. 


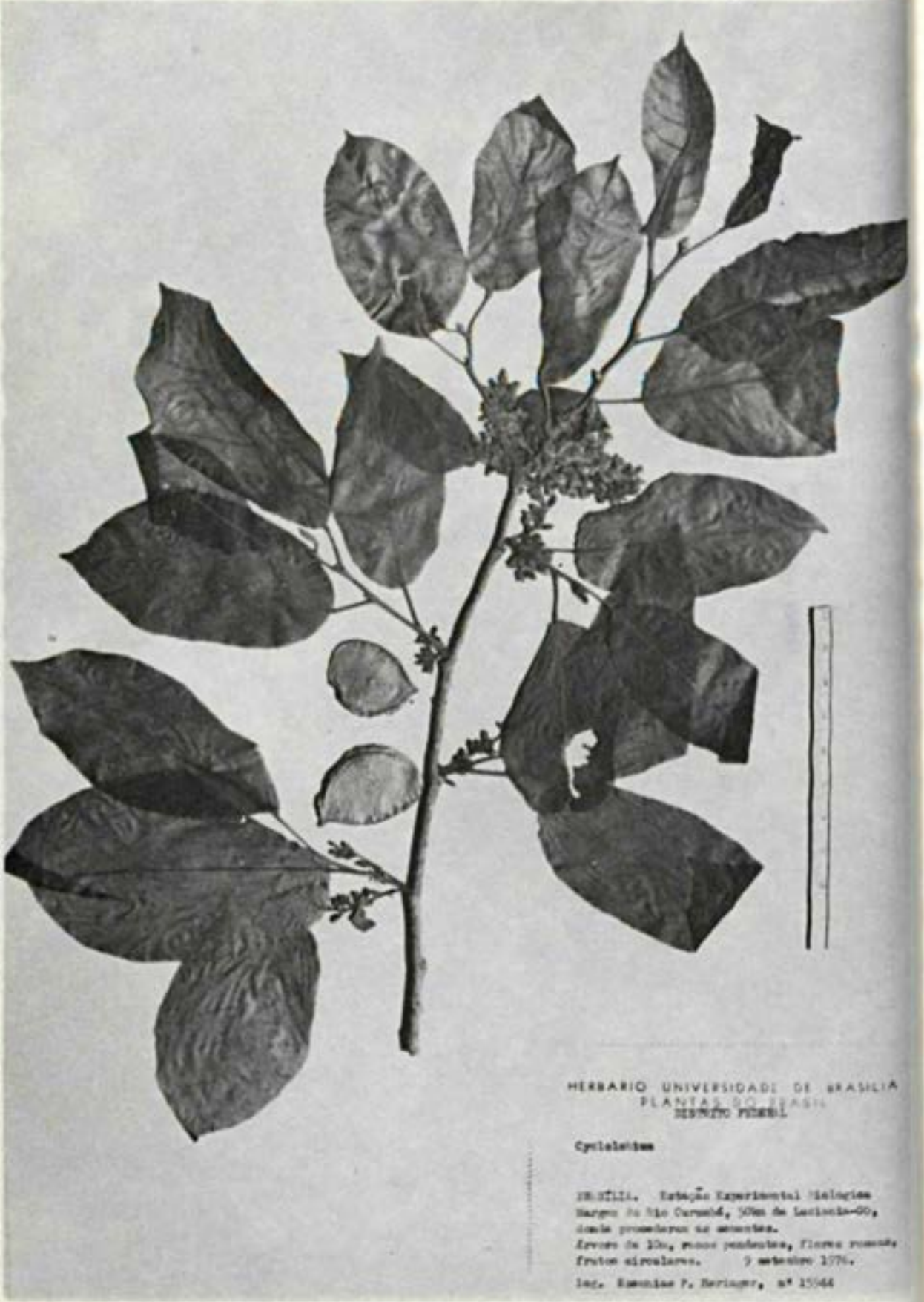

Fig. 6 - Cyclolobium nutans Rizz. \& Her. Folhas, flores e frutos. 


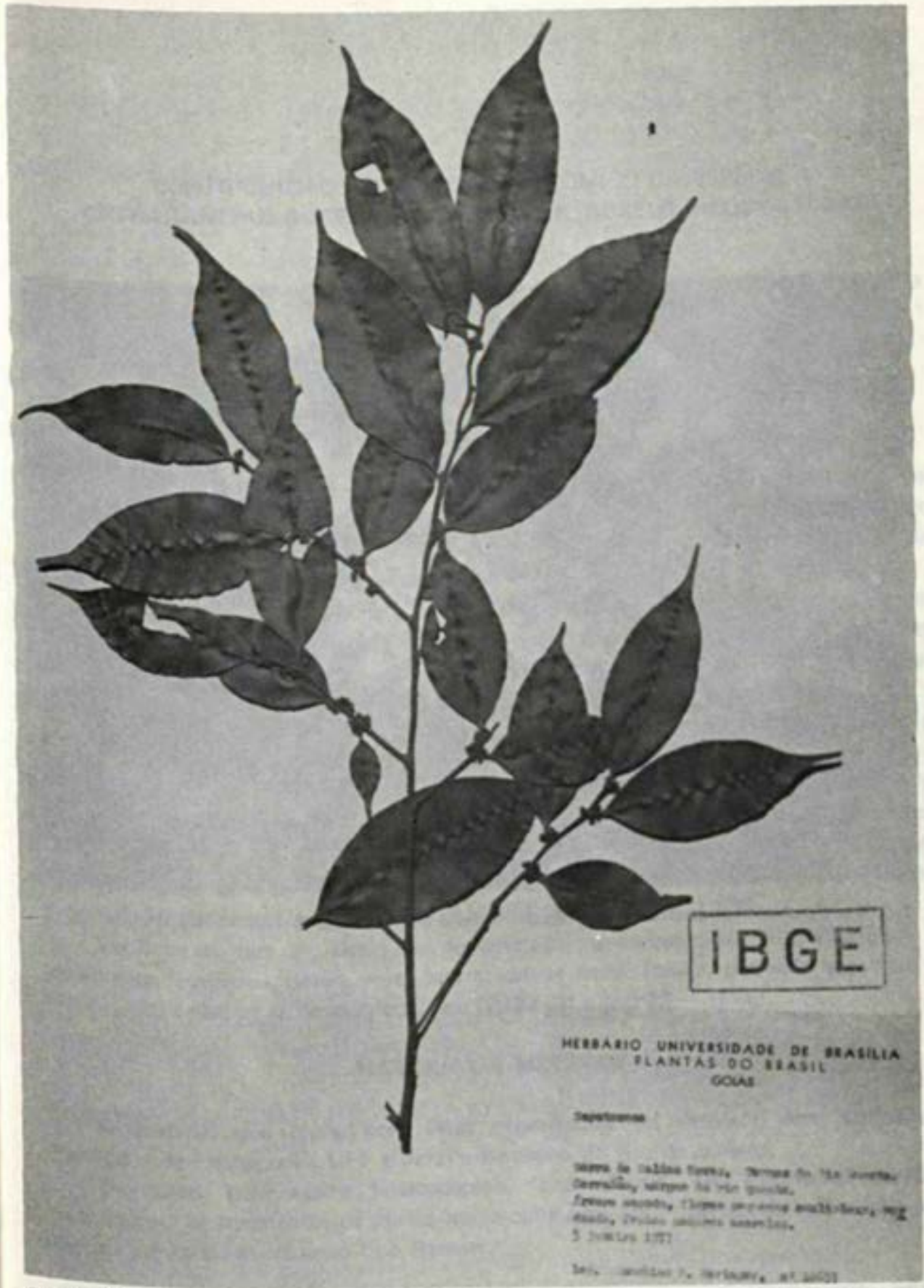

Fig. 7 - Pouteria undulatifolia Rizz. Folhas tipicas. 


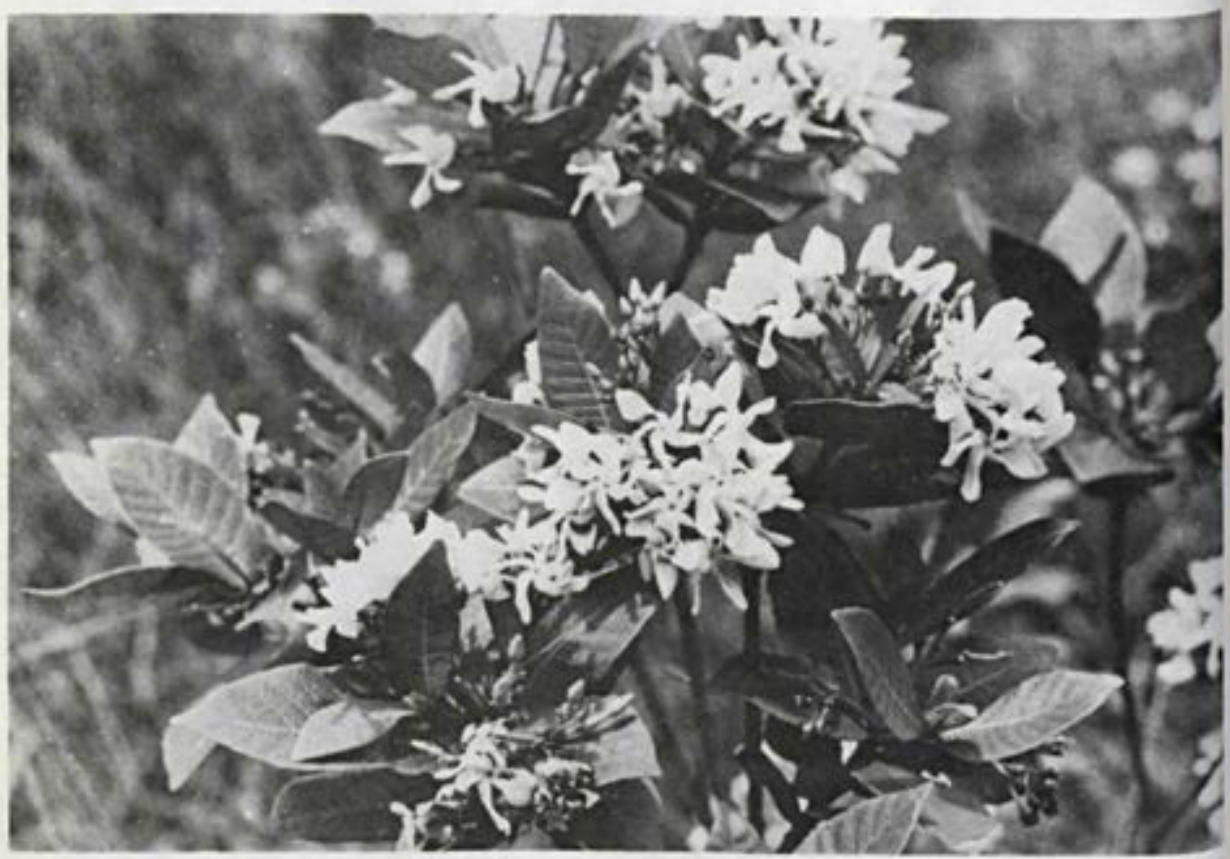

Fig. 8 - Aeschiera campestris (Rizz.) Rizz. Folhas e flores in natura. 